\title{
MATHEMATICAL MODELING OF THE VERTICAL BENDING PHENOMENA ON THE SHEET'S FRONT SECTION AT VARIOUS STAGES OF PLATE ASYMMETRICAL ROLLING
}

\author{
${ }^{1}$ Alexander PESIN, ${ }^{2}$ Denis CHIKISHEV, ${ }^{3}$ Denis PUSTOVOYTOV, ${ }^{4}$ Natalya LOKOTUNINA \\ Nosov Magnitogorsk State Technical University, Magnitogorsk, Russian Federation,

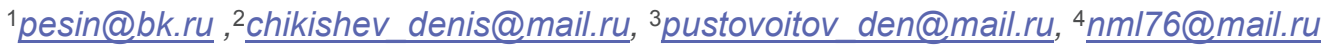

https://doi.org/10.37904/metal.2019.700

\begin{abstract}
The analysis of the causes of the ski-effect of the sheet in the hot rolling conditions in the plate mill 5000 was performed. Influence of kinematic, thermal and geometrical factors on the occurrence of the ski-effect of the sheet were investigated. Influence of the velocity asymmetry of work rolls on bending of the front end of a sheet was studied in detail. Influence of parameters of the rolling process and the velocity asymmetry of work rolls on the shape of the front end of the sheet for different passes were analyzed. Modes of asymmetric rolling alloy pipe steels in the plate mill 5000 were developed and simulated with using software DEFORM. The problem of flatness formation of the sheet was also studied. Industrial tests were performed in the plate mill 5000. Specific asymmetric rolling modes and recommendations for industry were developed. Results of research can be applied to any type of plate mill with independently adjustable velocity of the upper and lower work rolls.
\end{abstract}

Keywords: Asymmetrical rolling, plate rolling, finite element method, vertical bending, sheet's front section, temperature gradient

\section{INTRODUCTION}

In thick plate rolling, vertical bending of the front end of the strip often occurs. This is the so-called "ski" defect. The increased vertical bending of the front end leads to the "drilling" of the strip in the rollers of the pre-dressing machine and/or the roller table and, therefore, the mill stops. At the roughing stage of rolling, the main factor of asymmetry is temperature. The bottom surface of the slab is colder than the top. Therefore, during rolling, bending occurs in the direction of the lower (colder) surface. A significant temperature gradient is a difference of 10-15 degrees or more. Bending the roll down at the rough rolling stage leads to slippage between the rollers of the roller table and the lower surface of the strip (Figure 1). As a result, there are difficulties in manipulation. Therefore, to reduce the negative impact of temperature asymmetry on the thickness of the roll, the mismatch of the speeds of the work rolls is used [1-10].

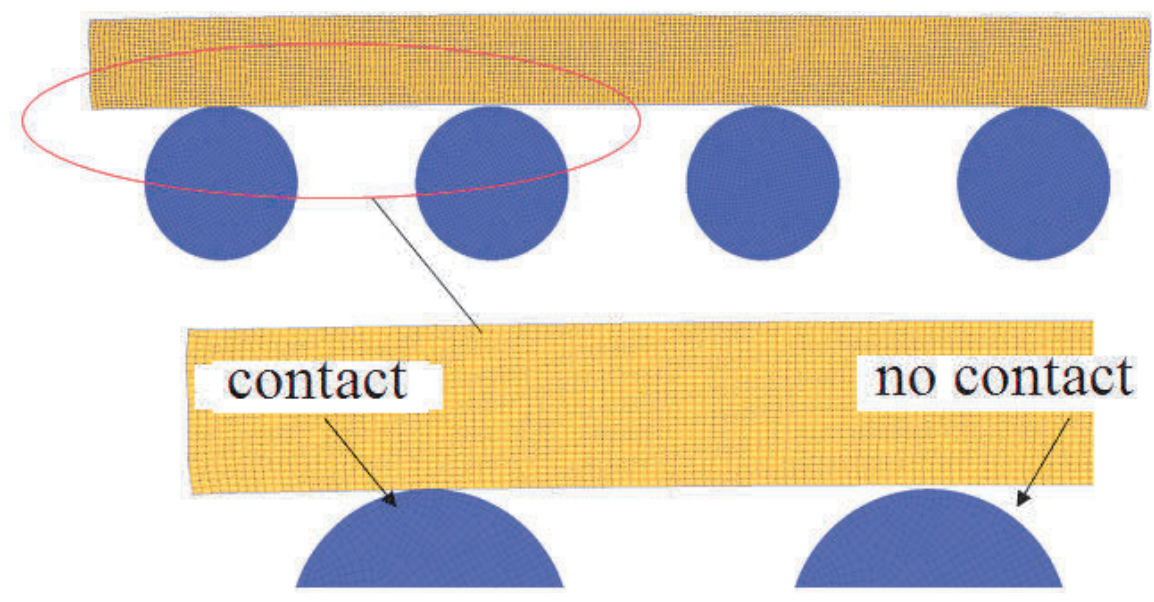

Figure 1 The reason for slipping between the rollers of the roller table and the lower surface of the strip 


\section{RESEARCH METHOD}

To describe and study the stress-strain state of the metal, a finite-element mathematical model was used. The mathematical model was adapted to the conditions of mill 5000 PJSC "MMK". Adaptation of this model consisted in the formulation of the boundary and initial conditions of the problem being solved. A number of assumptions of the modeled process were also taken. The following conditions were specified as boundary conditions: boundary surfaces of the instrument; the surface of the deformable material; the law of friction on contact with the working tool; rheological model of a deformable material. As the initial conditions for modeling, we specified: diameters and angular velocities of rotation of the work rolls; slab material flow curve; temperature of slab heating in the furnace; the initial dimensions of the slab; friction indicator on contact with work rolls; degree of deformation per pass; interdeformation pause time; ambient temperature; dimensions and number of finite elements, and other parameters. When modeling the plate rolling process, the following assumptions were made: the deformed state of the metal is flat; deformable environment - viscoplastic; incompressible rolls; friction stresses are proportional to shear yield. As a result of solving the problem, the following values were determined: temperature field along the length and thickness of the sheet after each deformation passage; the length of the front (rear) portion of the sheet, having a temperature gradient in thickness; the value of the vertical deviation of the front (rear) part of the sheet from the level of the roller table.

\section{SIMULATION RESULTS AND DISCUSSION}

It was found that to bend the roll up it is necessary to increase the speed of the lower roll by $1.0-8.0 \%$, depending on the steel grade and visual information. This is done manually. On the mill 5000 , automatic mode at the rough rolling stage is not provided. The main reason is the absence of lower pyrometers. Therefore, the magnitude of the mismatch of the speeds of the work rolls can only be set in manual mode (Figure 2).

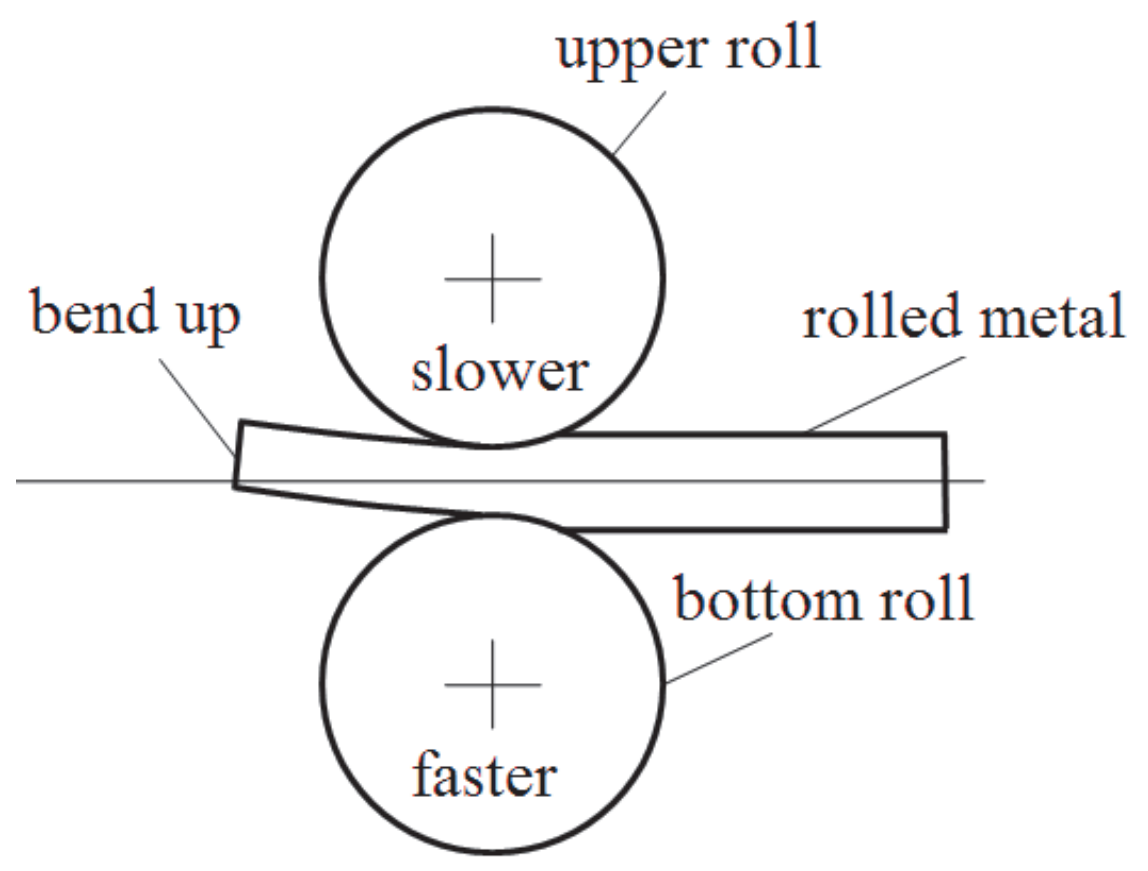

Figure 2 Bending scheme of the front end of the sheet

In some cases, the curvature of the front end of the roughing rolled metal is quite high. However, in the following deformation passages, the bend is reduced. The lower surface of the roll is colder due to the contact with the water-cooled rollers of the roller table and the turntable (Figure 3). 

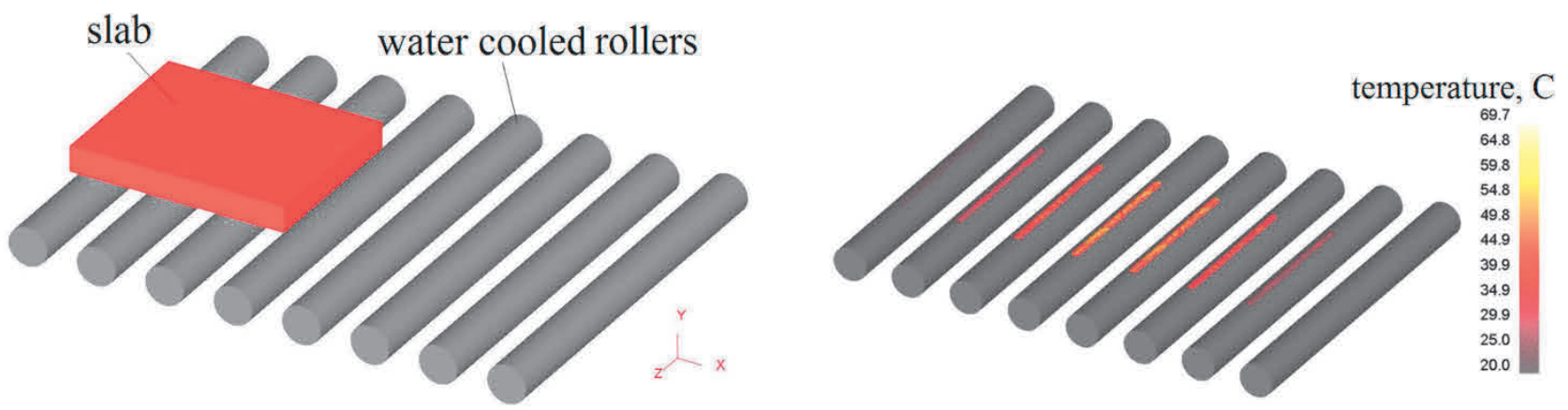

Figure 3 Warming up the rollers of the roller

The temperature gradient is formed along the entire length of the roll at the following stages: during transportation of the slab from the furnaces to the working stand; during the first phase of rolling; during cooling of the intermediate roll; during the second (third) phase of rolling. When transporting a slab from the furnace to the working stand, the temperature of the upper and lower surfaces of the slab changes in accordance with the schedule (Figure 4). Before the first deformation passage (first rolling phase), the temperature gradient between the upper and lower slab surfaces is 14-15 degrees (Figure 5).

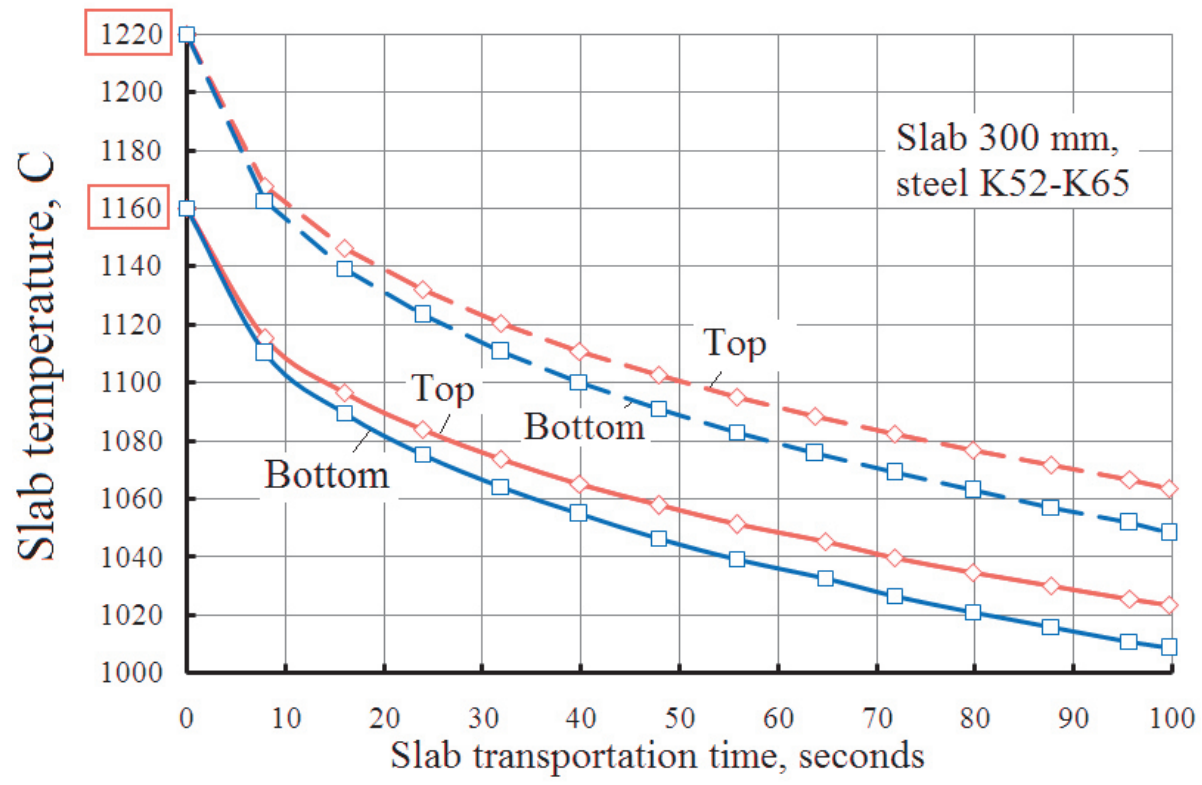

Figure 4 The graph of the temperature change of the upper and lower surface of the slab

Temperature, $\mathrm{C}$

$1040^{\circ} \mathrm{C}$

Top

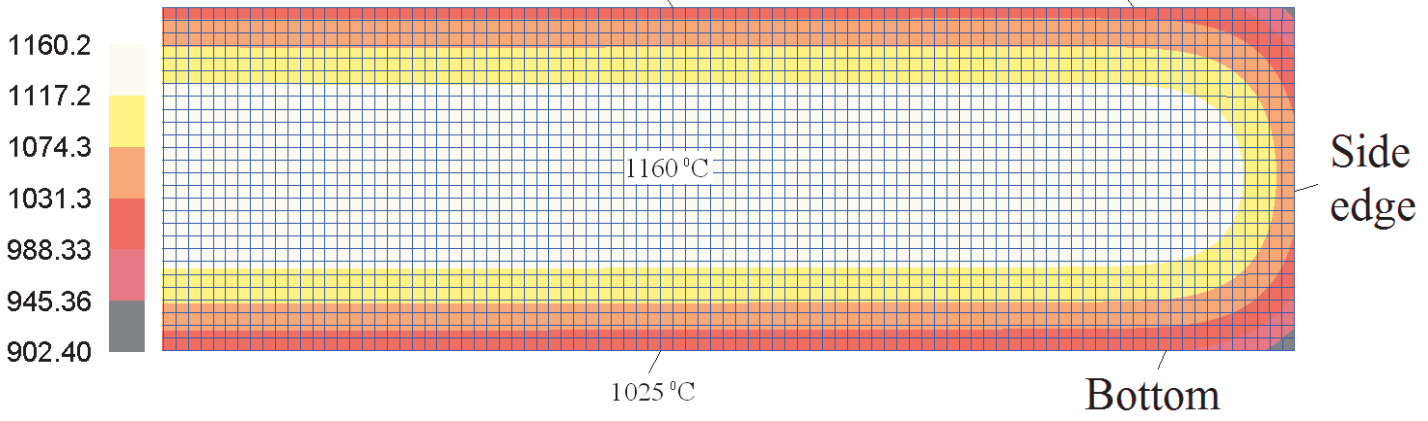

Figure 5 Temperature distribution over slab thickness before the first rolling pass 
If the slab has a colder lower surface, then when rolling without a mismatch of the speeds of the work rolls, the metal is displaced from the rolling line downwards. The greater the length of the metal, the greater the magnitude of the flatness in length. Bend rolled metal down due to a higher flow rate of the upper surface (more plastic) in comparison with the bottom (less plastic). When rolling with a mismatch of the speeds of the work rolls of $1.0 \%$ and $2.0 \%$ along the entire length of the roll, it bends upwards. The amount of bending upwards depends on the magnitude of the mismatch of the speeds of the work rolls, the temperature gradient between the upper and lower surfaces of the roll, the thickness of the roll, the reduction per pass, the length of the section where the velocity mismatch occurs. To obtain the required flatness along the length of the rolled metal, an exact choice of the mismatch of the speeds of the work rolls depending on the parameters of the rolling process is necessary. When rolling with a mismatch of speeds in the "bend of the ski" mode, the roll bends upwards only along the length of the ski. This is a case of rolling with a speed mismatch of $3.0 \%$ (the length of the ski is $1000 \mathrm{~mm}$; the temperature gradient is 15 degrees). The rest (the back of the roll) is deformed in the mode without a mismatch of the speeds of the work rolls and as a result the roll "pulls" down. Thus, a flatness along the length of the rolled metal is formed. The magnitude of the mismatch of the speeds of the work rolls should be sufficient for the formation of a curved up-front section of the rolled metal. The parameters for controlling the ski depend on the conditions of the rolling process. Thus, the formation of flatness along the length of the roll on the plate mill can be compensated by the use of various technological solutions. For example, due to the use of the mismatch of the speeds of the work rolls along the entire length of the rolled metal, depending on the rolling parameters (thickness of the roll, reduction per pass, temperature gradient, the magnitude of the mismatch of the speeds of the work rolls). Another option is to use the mismatch of the speeds of the work rolls only on the front section of the rolled metal (length of the ski) depending on the rolling parameters (thickness of the roll, reduction per pass, temperature gradient, size of the mismatch of the speeds of the work rolls; length of the roll before the pass, length of the ski). Consider the various options for the first phase of rolling steel $\mathrm{K} 60$. When rolling in 5 passes with a mismatch of the speeds of the work rolls of $1 \%$, a significant non-flatness is formed along the entire length of the rolled metal. When rolling in the "Fold of the ski" mode, a considerable flatness is observed only on the front section of the rolled metal, in the rest of the flatness is of a moderate nature. When rolling with a mismatch of speeds along the entire length, but with a certain amount of mismatch in each pass $(0.35 \% ; 0.40 \% ; 0.45 \% ; 0.50 \% ; 0.60 \%)$, the flatness of the rolled metal is minimal. During the first phase of rolling, the temperature gradient between the upper and lower surface of the roll increases by 3-5 degrees. Thus, when rolling in the first phase, the temperature gradient does not exceed 20 degrees (without taking into account the temperature gradient through the thickness of the slab at the exit of the furnace). During the cooling of the intermediate roll, the temperature gradient changes in accordance with the graphs (Figure 6).

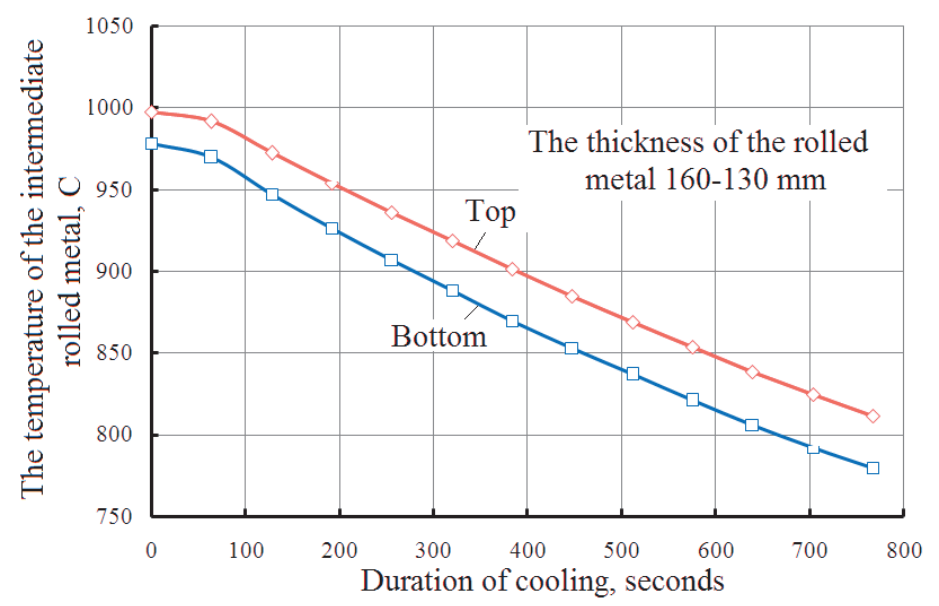

Figure 6 The graph of the temperature change of the upper and lower surface of the intermediate rolled metal 
During the interdeformation pause (200-900 seconds), the temperature gradient between the upper and lower surface of the intermediate rolled metal increases to 28-34 degrees. Thus, in the first finishing pass (the beginning of the second phase of rolling) the temperature gradient between the upper and lower surface of the roll is 28-34 degrees. Minimization of the rolled ends in mill 5000 conditions is possible due to the mismatch of the speeds of the work rolls in two modes - automatic and manual. The automatic mode is characterized by an insufficient working range of misalignment of the speeds of the work rolls (0-0.5\%). Manual mode, as opposed to automatic, has too large a range (1-15\%). The latter leads to overshoot and the occurrence of a defect "bend the ends up" at the rough rolling stage.

\section{CONCLUSION}

In this work, we studied in detail the influence of the magnitude of the mismatch of the speeds of the work rolls on the bending of the front section of the rough rolled metal. For this, over a thousand tons of rolled metal was analyzed. For each pass, the influence of the parameters of the rolling process and the magnitude of the mismatch of the speeds of the work rolls on the shape of the front end of the rolled metal were analyzed. The shape of the front ends of the rolled metal was evaluated visually (by photographing). Received full compliance with the actual shape of the front end with the predicted for these technological parameters of the process. This allowed us to develop quantitative recommendations to minimize the hem of the ends of the rolled metal at the rough rolling stage.

\section{ACKNOWLEDGEMENTS}

\section{The reported study was funded by RFBR according to the research project No 18-58-45013 IND_a and by a grant of the Russian Science Foundation (project No 15-19-10030)}

\section{REFERENCES}

[1] FARHAT-NIA, F., SALIMI, M., MOVAHHEDY, M.R. Elasto-plastic finite element simulation of asymmetrical plate rolling using an ale approach. Journal of Materials Processing Technology. 2006. vol. 177. pp. 525-529.

[2] RYDZ, D. The optimal conditions for production of bimetallic plate ST36K+0H13J in asymmetrical hot rolling. Journal of Materials Processing Technology. 2004. vol. 157-158. pp. 609-612.

[3] SALIMI, M., KADKHODAEI, M. Slab analysis of asymmetrical sheet rolling. Journal of Materials Processing Technology. 2004. vol. 150. pp. 215-222.

[4] MA, C., HOU, L., ZHANG, J., ZHUANG, L. Microstructures and properties of asymmetrical rolled 7050 al alloy plate with bending behavior optimization. Materials Science and Engineering: A. 2016. vol. 657. pp. 322-330.

[5] PESIN, A., PUSTOVOYTOV, D., PESIN, I., DRIGUN, E. Development of the technology of various large bodies manufacturing based on combined methods of deformation. Key Engineering Materials. 2016. vol. 716. pp. 659666.

[6] PESIN, A., DRIGUN, E., PUSTOVOYTOV, D., PESIN, I. Study of different large bodies manufacturing based on combined methods of deformation. In MATEC Web of Conferences: 3rd Asia Conference on Mechanical and Materials Engineering ACMME 2015, 2015. Article ID 03007.

[7] PESIN, A., PUSTOVOYTOV, D., PESIN, I., DRIGUN, E. Finite element modelling of combined process of plate rolling and stamping. In MATEC Web of Conferences: 12th International Conference on Numerical Methods in Industrial Forming Processes NUMIFORM 2016, 2016. Article ID 15008.

[8] RICHELSEN, A.B. Elastic-plastic analysis of the stress and strain distributions in asymmetric rolling. International Journal of Mechanical Sciences. 1997. vol. 39. pp. 1199-1211.

[9] WANG, H.Y., LI, X., SUN, J., WANG, Z.H., ZHAO, D.W., ZHANG, D.H. Analysis of sandwich rolling with two different thicknesses outer layers based on slab method. International Journal of Mechanical Sciences. 2016. vol. 106. pp. 194-208.

[10] ABOUTORABI, A., ASSEMPOUR, A., AFRASIAB, H. Analytical approach for calculating the sheet output curvature in asymmetrical rolling: in the case of roll axis displacement as a new asymmetry factor. International Journal of Mechanical Sciences. 2016. vol. 105. pp. 11-22. 